\title{
Spatiotemporal Analysis of Soil Moisture Drought over China during 2008-2016
}

\author{
Sovannaka Suon, Yi Li*, Lybun Porn, Tehseen Javed \\ College of Water Resources and Architectural Engineering, Northwest A \& F University, Yangling, China \\ Email: *liyi@nwsuaf.edu.cn
}

How to cite this paper: Suon, S., Li, Y., Porn, L. and Javed, T. (2019) Spatiotemporal Analysis of Soil Moisture Drought over China during 2008-2016. Journal of Water Resource and Protection, 11, 700-712. https://doi.org/10.4236/jwarp.2019.116041

Received: May 30, 2019

Accepted: June 15, 2019

Published: June 18, 2019

Copyright (อ 2019 by author(s) and Scientific Research Publishing Inc. This work is licensed under the Creative Commons Attribution International License (CC BY 4.0).

http://creativecommons.org/licenses/by/4.0/ (c) (i) Open Access

\begin{abstract}
Drought has been analyzed by various indices based on rainfall, temperature, evapotranspiration or soil moisture data. Remoste-sensing based data has spatial continuity with certain resolution and is useful for drought monitor. The purpose of this study was to investigate quality used of grid relative soil moisture, the spatial and temporal variation of soi moisture, and soil moisture drought based on relative soil moisture over China during 2008-2016. The results show that the relative soil moisture data set can reflect the spatial characteristics of the development of drought in China during 2008-2016. From the spatial distribution analysis, the northwest to northeast, south part of China, and other major arid areas, the performance is particularly evident. The results show that the use of CLDAS V1.0 real-time products, access to time and space continuous soil relative humidity products, can achieve the drought in China real-time monitoring.
\end{abstract}

\section{Keywords}

Soil Moisture, Soil Moisture Drought, Validation Assessment, Spatial Distribution

\section{Introduction}

Drought is the utmost distressed among natural catastrophes which resulted from the insufficient precipitation and soil moisture over long period of time [1] [2]. China is the third largest country in the area over the world and has been often suffered drought. Recently, increasing temperature, less in rainfall days in summer season caused the different climate regions and geographically suffered by drought [3]. Then the decreasing of storage water in soil layers led to the shortage in soil water content. Since the increasing population and economic facilities in China, so the food demand is a major subject [4]. Hence, it is vital to 
analyze drought considering the decreasing precipitation and soil moisture which the influenced agricultural production is a must [5].

Drought was attracted the interest by researchers and scientists due to its massive influence on ecology, environment, hydrology, and agricultural [6]. China has been affected by recurrent droughts for a long term [7]. The greatest dramatic drought occurred over the Southwest part of China in 2010 triggered water losses of 7599 ponds, 564 basins, and 744 streams (Yunnan, Bulletin of Water Resources). Around 27 million people had been suffered, 9.65 million people encountered the shortage of water, and $\$ 2.5$-billion rate of crops were lost [8].

With the global warming, global glaciers and more permafrost cover area are decreasing and drought disaster is increasing [9]. In the northwest of China, the past few decades of glacier departure, permafrost degradation not only changed ecological environment and microclimate environment, leading to runoff and runoff had provided the obvious changes, and as the glaciers continued to retreat, the arid and semi-arid areas of glacier meltwater runoff would eventually be seeming to reduce or even disappear, river runoff would also be affected [10] [11]. At this case, the drought disaster will occur more frequently. In agriculture aspects, soil drought not only directly led to a huge area of crop loss income, but also caused crop diseases, pests, and grassland fires [12] [13] [14]. Serious drought will reduce in agricultural products, lessen water resources, affect the agricultural structure, crop layout and planting system, and will lead to farmland, grassland desertification, national economy and ecological environment depletion [15]. Therefore, only active and reasonable monitoring of drought can take timely and effective precautionary measures to minimize the impact of drought on humans.

At present, soil moisture problems, mainly to take automatic observation station and satellite remote sensing of soil moisture were meant to monitor soil moisture drought. Chinese Bureau of the operation of automatic observation station of soil moisture, observed that soil moisture was applied to space around the observation station by spatial interpolation regional drought monitoring. Although these observations are accurate with high degree of reliability, because of the weather changes, season replacement and observation equipment itself, such as the installation of calibration and other reasons, data quality tended to be a variety of difficulties. The amount of automatic moisture stations also relatively limited and uneven distribution in eastern and western China. At present, it is not possible to simply use these site data to effectively monitor the nationwide of the drought situation.

The use of satellite remote sensing method to monitor drought can be divided into the use of optical remote sense and microwave remote sensing. Optical remote sensing by sensing to receive the multi-band spectral signal to be calculated, get the corresponding remote sense index [8], through the remote sensing index and soil moisture to establish a model. Therefore, to carry out drought monitoring, the microwave remote sensing technology is the use of microwave 
signals directly inversion of soil moisture, the use of soil moisture products to carry out follow-up monitoring.

Therefore, there is an urgent need for a set of time and space continuous, high resolution of soil moisture data to investigate the agricultural drought monitoring methods that can closely related to the growth of crops and product. Aim to assess the soil moisture drought in China, the study firstly was aimed to inspect the quality of using gird relative soil moisture data by comparing with observed data. Secondly, the purpose was focused on inspecting of the temporal variation of soil moisture over China during 2008-2016. Finally, the soil moisture drought will be analyzed based on relative soil moisture over China during 2008-2016.

\section{Materials and Methodology}

\subsection{Study Area}

China is the third largest country by area in the world with a total land area of $9,597,000 \mathrm{~km}^{2}$. China has a complicated geomorphology and a range of landscapes like water farmland, forests, mountains, deserts, reservoirs, water bodies, glaciers, and frozen soils [16]. China is divided into seven sub-regions by the discrepancies in topography and climate [17] i.e. the subregion 1-temperate and warm-temperate desert of Northwest China, subregion 2-Temperate grassland of Inner Mongolia, subregion 3-Warm-temperate humid and sub-humid Northeast China, subregion 4-Warm-temperate humid and sub-humid North China, subregion 5-Subtropical humid Central and South China, subregion 6-Qinghai-Tibetan Plateau, and subregion 7-Tropical humid South China. The weather stations are not uniformly distributed. There are sparse weather stations in Qinghai-Tibet Plateau, yet denser weather stations in eastern China. The location and elevations of the selected sites which covered a large range and sub-region division are revealed in Figure 1.

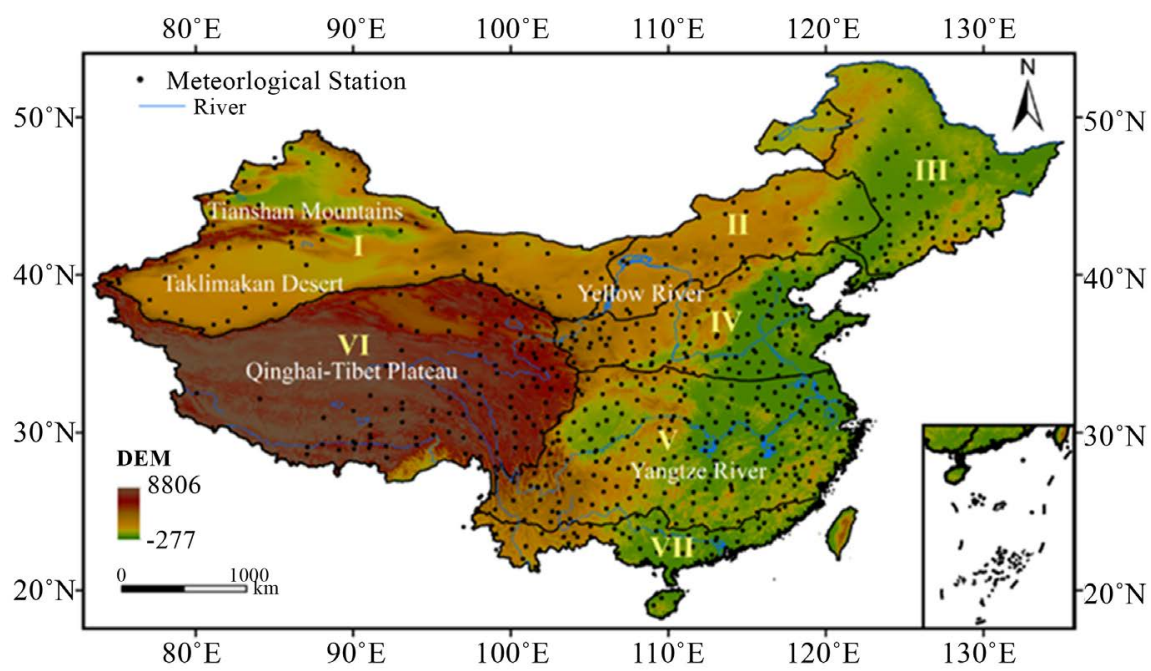

Figure 1. The elevation $(\mathrm{m})$ and location of the selected 774 national meteorological stations and different sub-regions in China. 


\subsection{Datasets}

\subsubsection{CLDAS Grid Soil Moisture Data}

This study utilizes the National Meteorological Information Center in November 2013 Released CLDAS V1.0 (China Meteorological Administration Land Data Assimilation System) soil volume water quantity products, combined with soil bulk density, field capacity and other related Information, inversion of a set of 2012 full time series of high spatial resolution rate of Chinese soil relative humidity data set, combined with "Chinese People's Republic of national standards: meteorological drought level" [18] over China, the drought based on soil moisture was monitored and analyzed.

CLM3.5 global surface parameter dataset is used to produce $1 / 16^{\circ}$ spatial resolution surface parameters of the East Asian region $\left(0^{\circ}-60^{\circ} \mathrm{N}, 70^{\circ} \mathrm{E}-150^{\circ} \mathrm{E}\right)$. The "CLDAS Atmospheric drive field V1.0" Dataset is used to spin-up the NCAR/CLM3.5 continental process model. The final state of the last simulated land surface mode is taken as the initial value, and the Atmospheric drive field is reused to drive the land surface model. So that it is repeated and the continental pattern equilibrium state is achieved.

Using the land surface mode state parameter after spin-up as the initial state, the CLM3.5 land surface mode is re-driven to obtain the liquid water weight of 10 layers of soil. In order to facilitate the application, the soil volume moisture content $\left(\mathrm{cm}^{3} / \mathrm{cm}^{3}\right)$ of $0-5,0-10,10-40,40-80$ and $80-200 \mathrm{~cm}$ was obtained by weighted average of the liquid water weight of 10 soil layers according to the thickness of each layer. Then, China Meteorological Administration began to establish automatic soil moisture observation network since 2009. The data included soil moisture $\left(\mathrm{cm}^{3} / \mathrm{cm}^{3}\right)$ then converted to average monthly relative soil moisture (\%) during 2008-2016.

\subsubsection{Observed Soil Moisture Data}

Monthly observation-based weather data from 773 meteorological observation stations were obtained from the China Meteorological Data Sharing Service System (http://data.cma.cn/) including relative soil moisture (\%) from 2008 to 2016.

\subsection{Drought Index Algorithm}

According to the "Meteorological Drought Drade" national standard, soil relative humidity drought index is one of the indicators that reflect the soil water content (Table 1), suitable for a moment of soil moisture profit and loss monitoring. The standard uses the surface $20 \mathrm{~cm}$ depth of soil relative humidity, the scope of application for dryland crops area. Due to different soil properties of soil relative humidity there is a certain difference can be made according to the local soil properties when appropriate adjustment. The relative soil moisture index of soil is calculated as follows:

$$
R_{s m}=\frac{w}{f_{c}} \times 100 \%
$$


Table 1. Classification of drought level by relative soil moisture $\left(\mathrm{R}_{\mathrm{sm}}\right)$.

\begin{tabular}{cc}
\hline Type & Relative soil moisture, $\mathrm{R}_{\mathrm{sm}}(\%)$ \\
\hline No drought & $\mathrm{R}_{\mathrm{sm}}>60 \%$ \\
Light drought & $50 \%<\mathrm{R}_{\mathrm{sm}}<60 \%$ \\
Moderate & $40 \%<\mathrm{R}_{\mathrm{sm}}<50 \%$ \\
Severe drought & $30 \%<\mathrm{R}_{\mathrm{sm}}<40 \%$ \\
Extreme drought & $\mathrm{R}_{\mathrm{sm}}<30 \%$ \\
\hline
\end{tabular}

$$
w=\frac{\theta_{v}}{\rho}
$$

where $R_{s m}$ represents relative soil moisture (\%), $w$ indicates soil weight water-bearing quantity (\%), $\theta_{v}$ is soil volume water content $\left(\mathrm{g} \cdot \mathrm{cm}^{-3}\right), \quad \rho$ (Rho) is soil bulk weight $\left(\mathrm{g} \cdot \mathrm{cm}^{-3}\right)$, and $f_{c}$ demonstrates field capacity of water hold (\%) for soil fields.

\subsection{Validation Assessment}

The data of this observation is made by the China Meteorological Data Sharing Service System was used to validate the quality use of CLDAS V1.0 grid soil moisture data. The validation period was during 2008-2016. Root mean square error (RMSE), and $R^{2}$ were used [19] [20], the formula for RMSE and $R^{2}$ were followed by:

$$
\begin{gathered}
\text { RMSE }=\sqrt{\frac{\sum_{i=1}^{N}\left(x_{i}-y_{i}\right)^{2}}{N}} \\
R^{2}=\frac{\sum_{i=1}^{N}\left(x_{i}-\bar{x}\right)\left(y_{i}-\bar{y}\right)}{\sqrt{\sum_{i=1}^{N}\left(\left(x_{i}-\bar{x}\right)^{2}\right)} \sqrt{\sum_{i=1}^{N}\left(\left(y_{i}-\bar{y}\right)^{2}\right)}}
\end{gathered}
$$

in which $N$ indicated the length of data in time series while $x_{i}$ and $y_{i}$ stand from two compared datasets at time $i$ for each grid, respectively. $\bar{x}$ and $\bar{y}$ are the average values of corresponding data.

\subsection{Ordinary Kriging ( $\mathrm{OK})$}

Ordinary Kriging (OK) have been used to inspect the spatial distribution analysis of relative soil moisture. Ordinary Kriging is one of the most basic of Kriging methods. It provides an estimate at an unobserved location of variable $\mathrm{z}$, based on the weighted average of adjacent observed sites within a given area. The theory is derived from that of regionalized variables and can be briefly described by considering an intrinsic random function denoted by $z\left(s_{i}\right)$, where si represents all sample locations, $i=1,2, \ldots, \mathrm{n}$. An estimate of the weighted average given by the ordinary Kriging predictor at an unsampled site $z\left(s_{0}\right)$ is defined by: 


$$
Z\left(s_{0}\right)=\sum_{i=1}^{n} \lambda_{i} z\left(s_{i}\right)
$$

where, $\lambda$ are the weights assigned to each of the observed samples. These weights sum to unity so that the predictor gives and unbiased estimation:

$$
\sum_{i=1}^{n} \lambda_{i}=1
$$

The weights are calculated from the matrix equation:

$$
C=A^{-1} \times b
$$

where:

$A=$ A matrix of semi ariances between the data points.

$b=\mathrm{A}$ vector of estimated semivariances between the data points and the points at which the variable.

$Z$ is to be predicted.

$C=$ The resulting weights.

\section{Results}

\subsection{Validation Analysis}

In this study, the Ordinary Kriging (OK) interpolation method was used to analyze and map the spatial distribution of relative soil moisture (\%) over China during 2008-2016. Figure 2 shows the spatial distribution of average annual relative soil moisture.

Figure 2 the green and red were indicated the high and low amount of relative soil moisture, respectively. The dark green was showed the maximum of relative soil moisture and the dark red demonstrated the lowest amount of relative soil moisture. However, Figure 3 showed the value of RMSE (\%) which the green indicated the higher and red indicated the lower.

The RMSE (\%) values of average monthly relative soil moisture were mapped

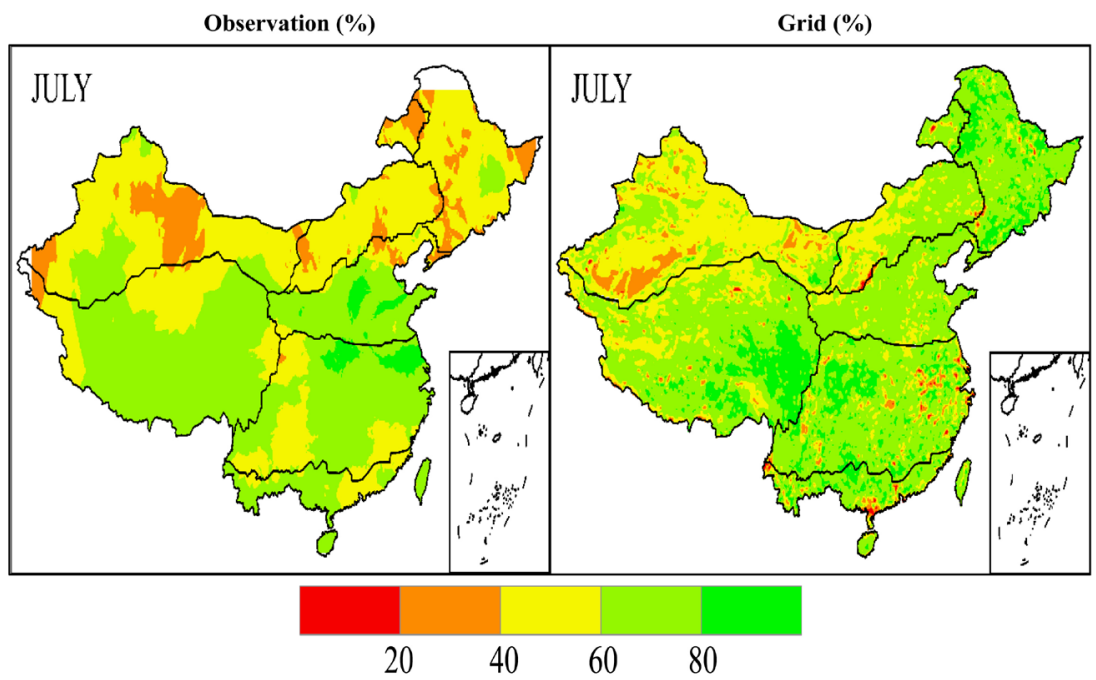

Figure 2. Spatial distribution of average monthly relative soil moisture during 2008-2016. 


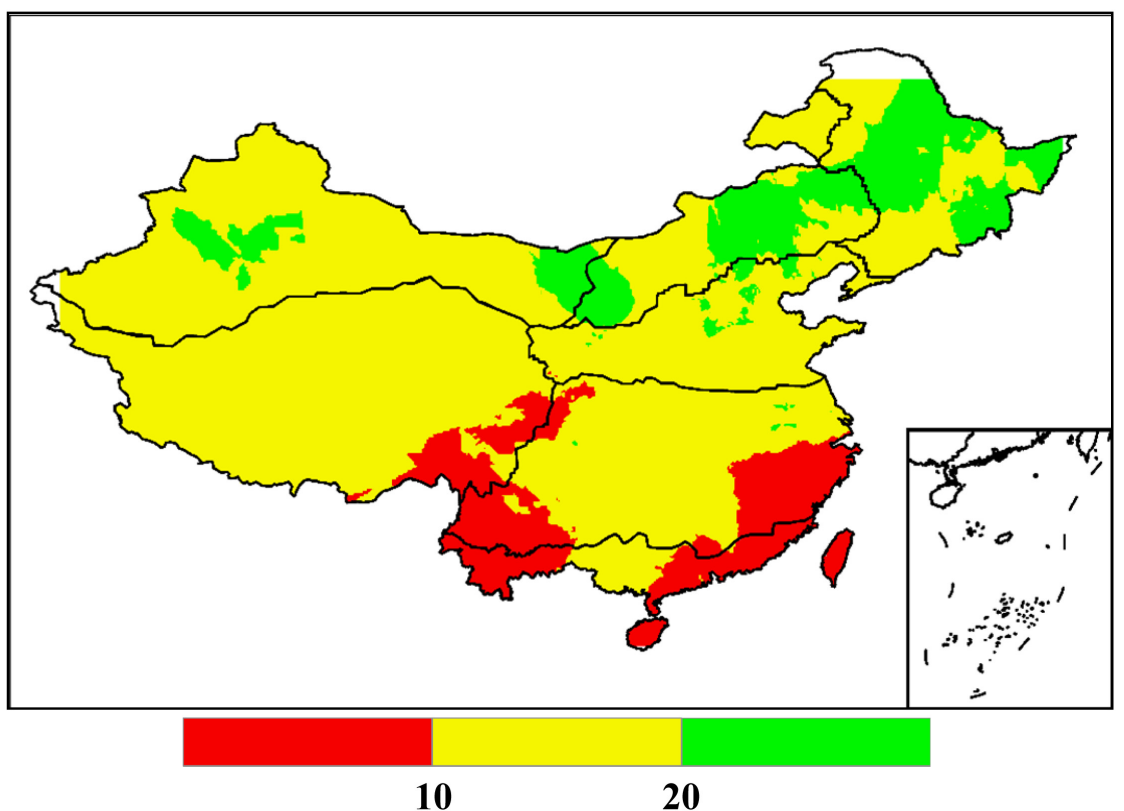

Figure 3. Spatial distribution of RMSE (\%) between observed and grid relative soil moisture during 2008-2016.

in Figure 3, and $\mathrm{R}^{2}$ values also demonstrated in Figure 4 and Figure 5. The relative soil moisture typically showed alike patterns between observed and grid data for almost whole China, with generally small RMSE $(<30 \%)$. This demonstrated that the remote sesing grid soil moisture data quality was accurate and reliable.

\subsection{Temporal Analysis of Relative Soil Moisture}

The temporal variations of average monthly relative soil moisture at the $20 \mathrm{~cm}$ depth are shown in Figure 5. At the monthly timescale in all sub-regions, relative soil moisture varied occasionally with randomness. Monthly relative soil moisture varied from month to month, although the maximum amount variations patterns differed from each year. The highest monthly relative soil moisture had sharp in July at sub-regions 5 and 7 in 2016 and lowest at sub-region 1 in 2008, these are reasonable because sub-region 5 and 7 represents the semi-humid and humid areas while sub-region 1 indicates the arid area which shortage of raining days. The range of relative soil moisture is fill in percentage (0\% - 100\%). The maximum relative soil moisture receives in summer (June, July and August) and the lowest is in winter season (December, January, and February). Relative soil moisture has regional variations, normally with a cumulative rank from sub-region 1 to 2, 4, 6, 3, 5 and 7 which sub-region 1 and 2 were ranked from $0 \%$ - 50\%, sub-region 4 was ranked from $0 \%-60 \%$, sub-region 6 was ranked as $0 \%$ $62 \%$, sub-region 3 was ranked as $0 \%-77 \%$, sub-region 5 and 7 were ranked from $0 \%-79 \%$. At monthly scale, sub-region 7 received the peak relative soil moisture (79\%) in July during 2008-2016. On the contrary, sub-region 1 received the lowest precipitation and thus low soil moisture. Obviously, the minimum relative soil moisture is $18 \%$ in January of 2008. 


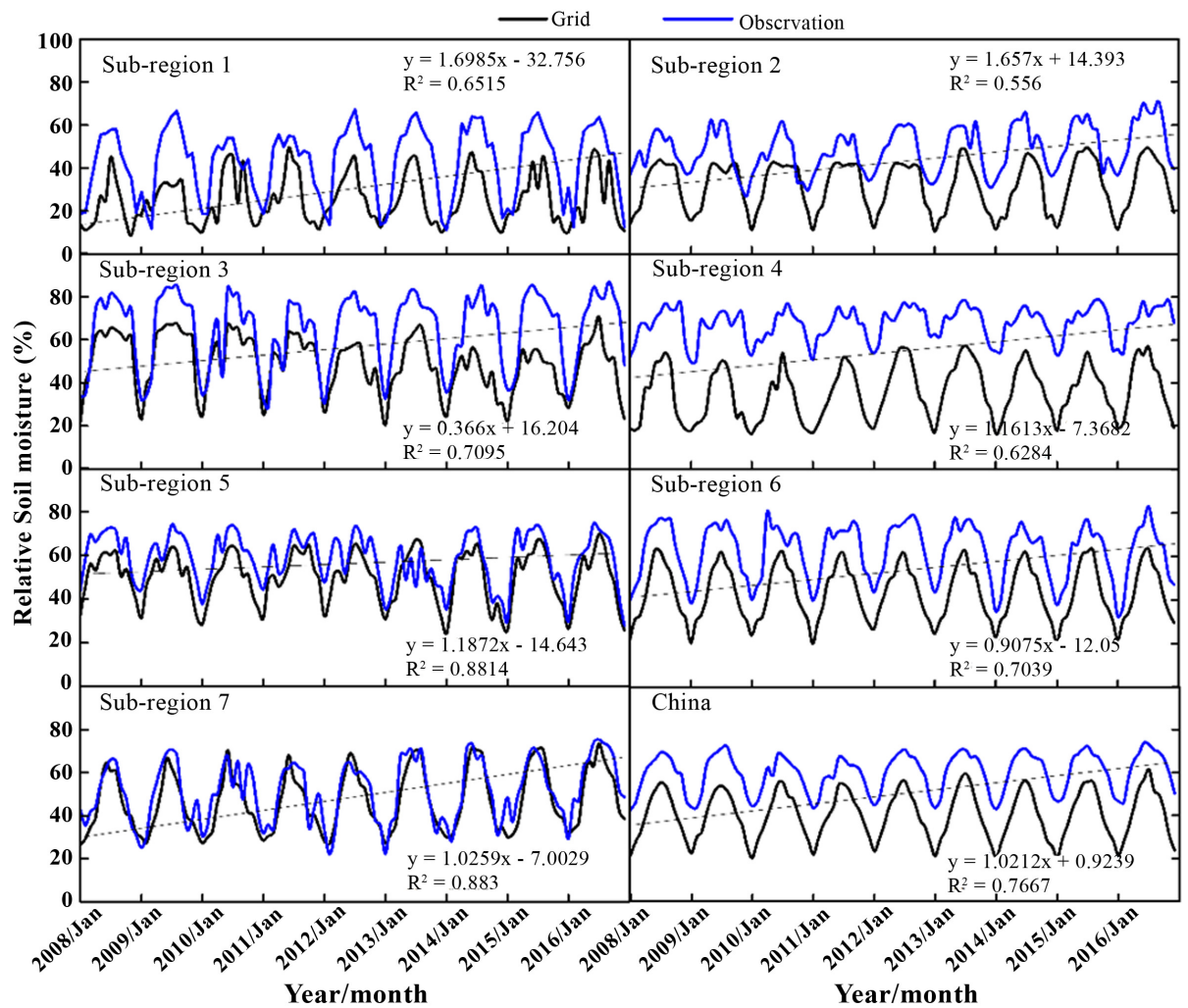

Figure 4. Monthly variation of observed and grid relative soil moisture for different sub-regions and China during 2008-2016.

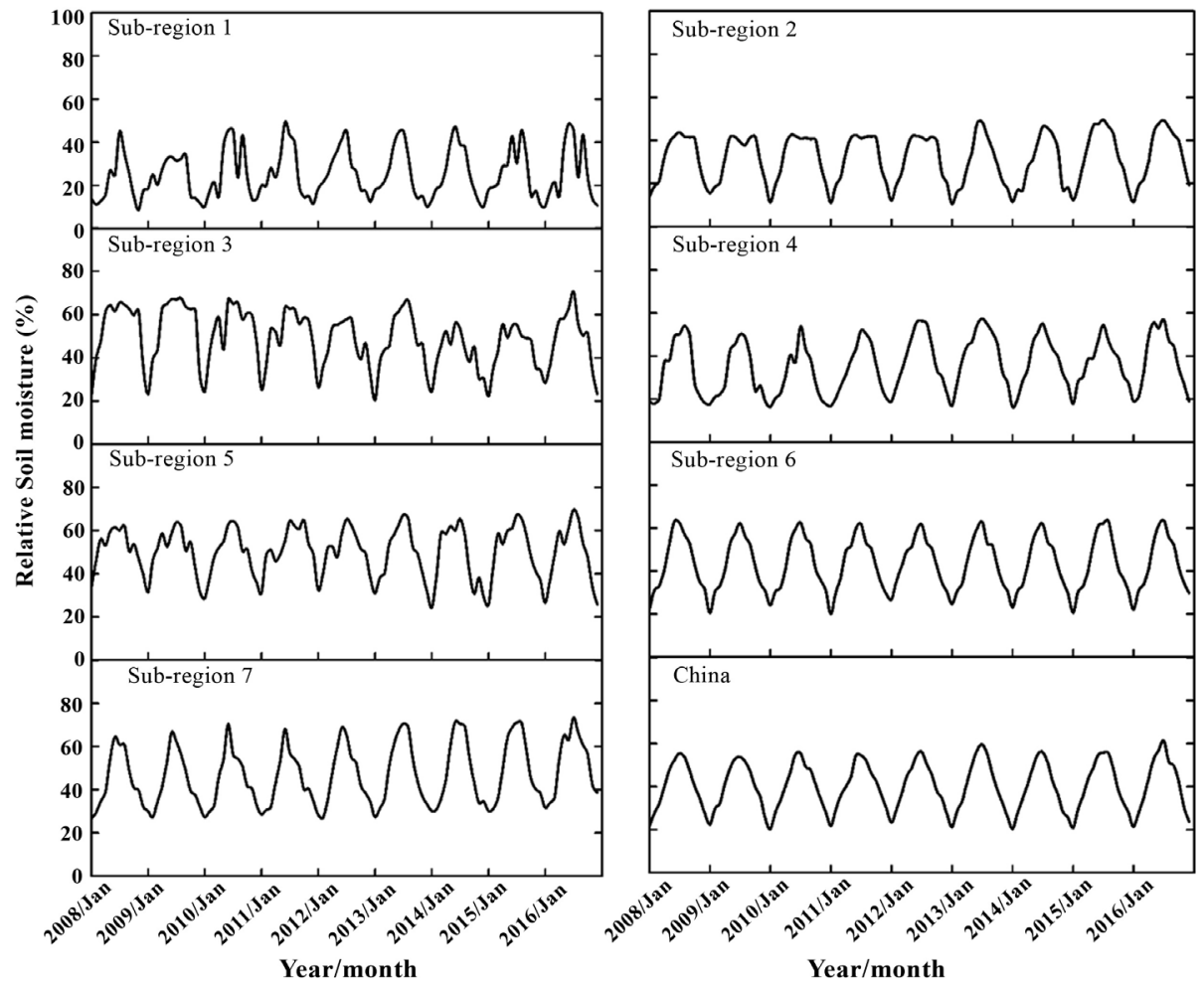

Figure 5. Temporal variation of monthly relative soil moisture for different sub-regions and China during 2008-2016. 
The seasonal change of relative soil moisture illustrates at different sub-regions in Figure 5. Few oscillations of seasonal average relative soil moisture were observed once compared to the monthly amount.

The variations of annual average relative soil moisture are demonstrated Figure 6. Compare to Figure 2 and Figure 3, sub-regions 1 has the lowest variation of relative soil moisture. Sub-region 7 establishes the highest annual average relative soil moisture with value of $78 \%$, indicating humid conditions of south China. Meanwhile, sub-region 1 had the lowest values of annual average relative soil moisture of $41 \%$ in 2008 (Figure 7).

\subsection{Soil Moisture Drought Assessment}

Average monthly relative soil moisture over China have been analyzed and mapped in Figure 8. Due to the shortage of relative soil moisture led to soil moisture drought occurrence during the study periods. Spatial distribution of monthly soil moisture drought has been analyzed using Ordinary Kriging (OK) in GIS software. According to Figure 8, the severe and extreme soil moisture drought occurred for most of the months during 2008-2016. Additionally, in Winter (January, February, March) occurred the extreme drought for most of the sub-region 1 (arid area), sub-region 2 (semi-arid), and sub-region 3 which
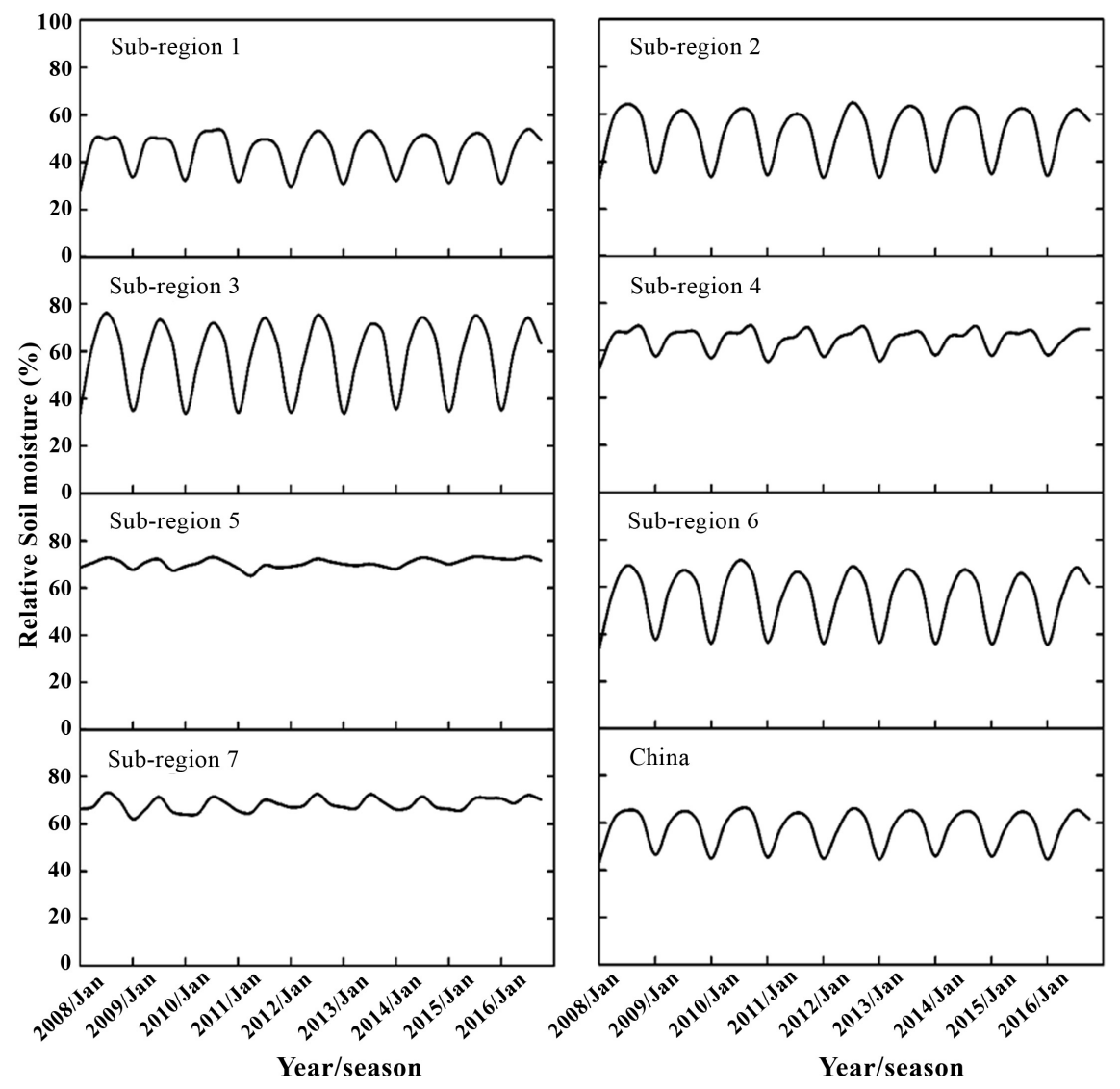

Figure 6. Temporal variation of seasonal average relative soil moisture for different sub-regions and China during 2008-2016. 


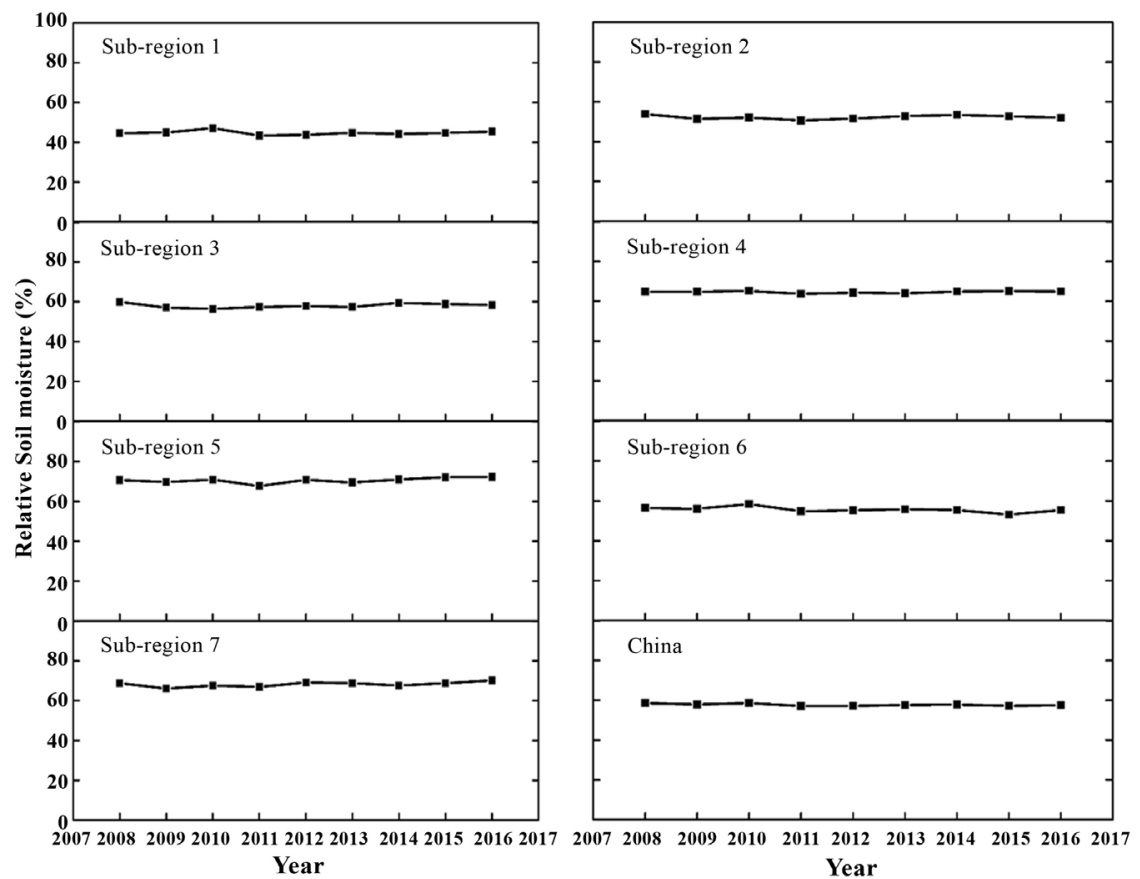

Figure 7. Temporal variation of annual average relative soil moisture for different sub-regions and China during 2008-2016.

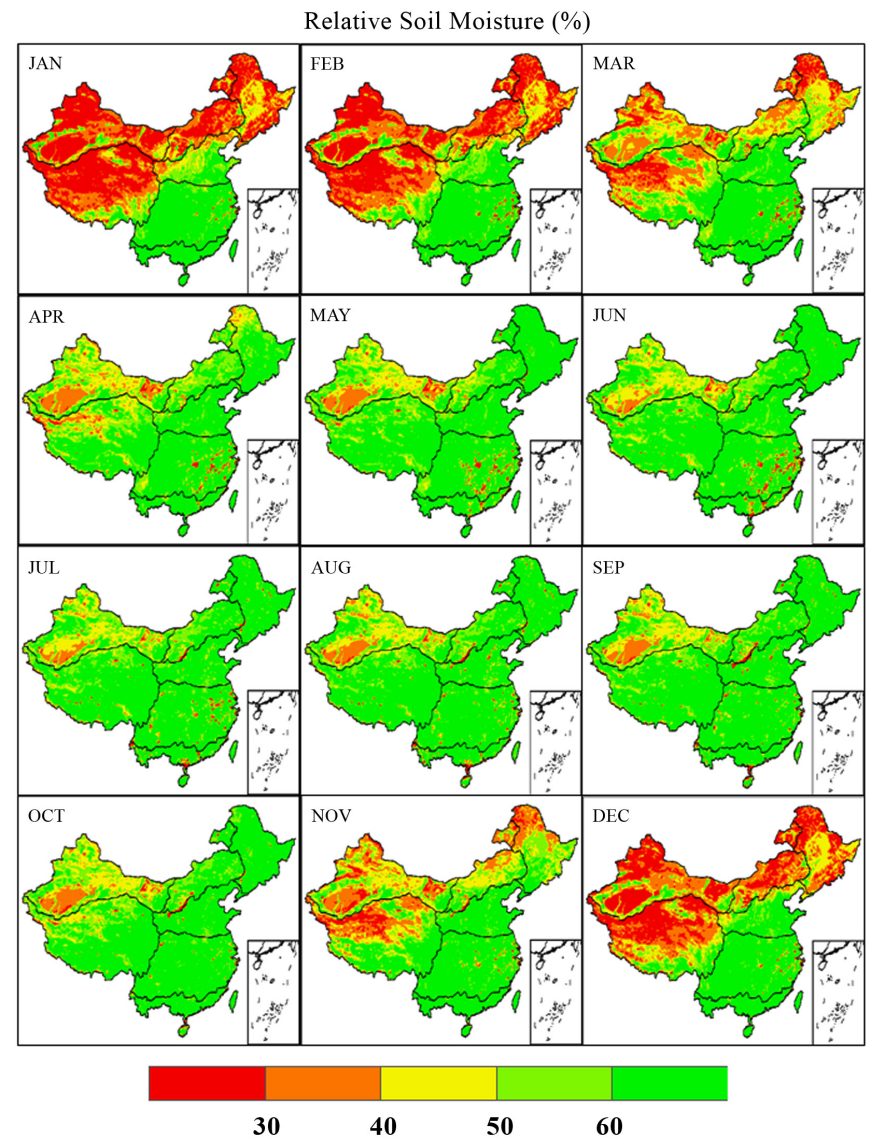

Figure 8 . The spatial distribution of average monthly relative soil moisture at $20 \mathrm{~cm}$ depth during 2008-2016. 
located in the northwestern, northern, and northeastern part of China. Dry areas were located in northwestern and northern China with the minimum relative soil moisture $(<30 \%)$, which have been indicated by the previous research that obtained the average monthly soil moisture of $25 \%$ [21].

In this case, the soil sooner meets the serious water shortage state, the crop vegetation basically unable to absorb the insufficient water from the soil which then seriously affect agricultural production. Yet, the record humid areas were located in the Yangtze River basin, Northeast Plain, and southern part of the country which average monthly relative soil moisture were larger than $50 \%$. The relative soil moisture in the Western and Yunnan regions of Guangxi has reached under 50\%, began appearing light to mild drought. In central and eastern Henan the area gradually entered late spring and early summer, accompanied by a moderate intensity of drought.

At the same time, in the Northeast region, especially in northeastern Inner Mongolia, Hei Long Jiang, Northern Jiangxi and other regions, there has also been a severe drought. Inner Mongolia, Tongliao and the western part of Songnen Plain suffered by mild drought. The relative soil moisture is less than $60 \%$, in the state of light drought, some areas which appeared relative soil moisture less than $50 \%$, drought is heavier in Heilongjiang Daxing.

\section{Discussions}

From the spatial distribution map of this study, it can basically to monitor the drought. Local areas were compared to the monitoring bulletin, the computation the degree of drought was slightly low, the initial judgment may be due to the majority of Southwest Sichuan. For mountainous areas, soil properties vary greatly, and the soil density of lattice pointing and the water holding in the field can not show the complexity of its soil topography in detail. Therefore, the effect of drought monitoring needs to be improved.

This paper used CLDAS V1.0 which provided by the National Meteorological Information Center. Volumetrice soil moisture $\left(\mathrm{cm}^{3} / \mathrm{cm}^{3}\right)$ products converted into relative soil moisture (\%) products. By using relative soil moisture data as soil moisture drought monitoring index to analyze regional drought events during 2008-2016 over in China.

The results show that this product can provide space-time continuous soil moisture data, combined with the hydrological parameters of soil that can effectively realize the wide range of drought monitoring in a continuous period of time and space. Because the index calculated in this paper is mainly aimed at crop soil drought testing, while in winter, much of the northern part of the north is covered with snow and ice, frozen soil, and due to the Northwest Desert, plateau and other complex terrains, surface soil. The spatial variability of hydrological parameters of soil is large, and the measured data obtained are more less, it is difficult to calculate and obtain accurately through the soil transfer transformation function, so it is not appropriate to use this standard for monitoring in 
the northern part of winter. With the observation, the increase of the site, the more accurate acquisition of soil hydrological parameters will also greatly improve the capacity of drought monitoring in the Northwest Territories. In recent years, along with the land surface data assimilation system of various countries. The research continues to deepen, relying on the land surface process simulation to obtain the volumetric soil moisture becomes possible.

\section{Conclusion}

On the basic of CLDAS V1.0, the National Meteorological Information Center will continue to develop many land surface model simulations, satellite temperature data assimilation and other subsequent editions to make the simulation of soil moisture more accurate. But drought disasters are a complex phenomenon involving agriculture, meteorology, hydrology, vegetation physiology and many other disciplines, the needs for multi-disciplinary branch communication, multi-element and the common consideration can be more comprehensive inclusion of crops, soil, atmosphere, and other elements. Therefore, to study drought, soil moisture, rainfall, streamflow, and a combination of many drought indicators are important to make drought monitoring more accurate and reliable.

\section{Acknowledgements}

This study was financially supported by the Natural Science Foundation of China (Nos. 41850410496 and 51579213), and the China 111 Project (No. B12007).

\section{Conflicts of Interest}

The authors declare no conflicts of interest regarding the publication of this paper.

\section{References}

[1] Van Genderen, J.L. (2012) Drought: Past Problems and Future Scenarios. International Journal of Digital Earth, 5, 456-457. https://doi.org/10.1080/17538947.2011.597110

[2] Wilhite, D.A. and Buchanan-Smith, M. (2005) Drought as Hazard: Understanding the Natural and Social Context. In: Drought and Water Crises, CRC Press, Boca Raton, 3-20.

[3] Chen, H. and Sun, J. (2015) Changes in Drought Characteristics over China Using the Standardized Precipitation Evapotranspiration Index. Journal of Climate, 28, 5430-5447. https://doi.org/10.1175/JCLI-D-14-00707.1

[4] Brown, R.L. and Halweil, B. (1998) China's Water Shortage Could Shake World Food Security. World Watch, 11, 10-16.

[5] Vermeulen, S.J., Campbell, B.M. and Ingram, J.S.I. (2012) Climate Change and Food Systems. Annual Review of Environment and Resources, 37, 195-222. https://doi.org/10.1146/annurev-environ-020411-130608

[6] Keshavarz, M.R., Vazifedoust, M. and Alizadeh, A. (2014) Drought Monitoring Using a Soil Wetness Deficit Index (SWDI) Derived from MODIS Satellite Data. 
Agricultural Water Management, 132, 37-45.

https://doi.org/10.1016/j.agwat.2013.10.004

[7] Yao, N., Li, Y., Lei T.J. and Peng, L.L. (2018) Drought Evolution, Severity and Trends in Mainland China over 1961-2013. Science of the Total Environment, 616-617, 73-89. https://doi.org/10.1016/j.scitotenv.2017.10.327

[8] Qiu, J. (2010) China Drought Highlights Future Climate Threats. Nature, 465, 142-143. https://doi.org/10.1038/465142a

[9] Raj, B. and Singh, O. (2012) Study of Impacts of Global Warming on Climate Change: Rise in Sea Level and Disaster Frequency. In: Singh, B.R., Ed., Global Warming: Impacts and Future Perspective, IntechOpen, London.

[10] Niu, L., Ye, B.Y., Ding, Y.J., Li, J., Zhang, Y.S., et al. (2016) Response of Hydrological Processes to Permafrost Degradation from 1980 to 2009 in the Upper Yellow River Basin, China. Hydrology Research, 47, 1014-1024. https://doi.org/10.2166/nh.2016.096

[11] Bibi, S., Wang, L., Li, L.P., Zhou, J., Chen, D.L. and Yao, T.D. (2018) Climatic and Associated Cryospheric, Biospheric, and Hydrological Changes on the Tibetan Plateau: A Review. International Journal of Climatology, 38, e1-e17. https://doi.org/10.1002/joc.5411

[12] Xing, W., et al. (2017) Spatial-Temporal Variation of Glacier Resources in Chinese Tianshan Mountains since 1959. Acta Geographica Sinica, 72, 1594-1605.

[13] Liu, S., et al. (2015) The Contemporary Glaciers in China Based on the Second Chinese Glacier Inventory. Acta Geographica Sinica, 70, 3-16.

[14] Zhang, W., Jin, F.F. and Turner, A. (2014) Increasing Autumn Drought over Southern China Associated with ENSO Regime Shift. Geophysical Research Letters, 41, 4020-4026.

[15] Shen, Y. and Wang, G. (2013) Key Findings and Assessment Results of IPCC WGI Fifth Assessment Report. 35, 1068-1076.

[16] Li, L., Yao, N., Li, Y., Liu, D.L., Wang, B., et al. (2019) Future Projections of Extreme Temperature Events in Different Sub-Regions of China. Atmospheric Research, 217, 150-164. https://doi.org/10.1016/j.atmosres.2018.10.019

[17] Wang, Y., Jiang, T., Bothe, O. and Fraedrich, K. (2006) Changes of Pan Evaporation and Reference Evapotranspiration in the Yangtze River Basin. Theoretical and Applied Climatology, 90, 13-23. https://doi.org/10.1007/s00704-006-0276-y

[18] Li, Y., Wu, W.X., Ge, Q.S., Zhou, Y., et al. (2016) Simulating Climate Change Impacts and Adaptive Measures for Rice Cultivation in Hunan Province, China. Journal of Applied Meteorology and Climatology, 55, 1359-1376. https://doi.org/10.1175/JAMC-D-15-0213.1

[19] Spadavecchia, L. and Williams, M. (2009) Can Spatio-Temporal Geostatistical Methods Improve High Resolution Regionalisation of Meteorological Variables? Agricultural and Forest Meteorology, 149, 1105-1117. https://doi.org/10.1016/j.agrformet.2009.01.008

[20] Karl, J.W. (2010) Spatial Predictions of Cover Attributes of Rangeland Ecosystems Using Regression Kriging and Remote Sensing. Rangeland Ecology \& Management, 63, 335-349. https://doi.org/10.2111/REM-D-09-00074.1

[21] Meng, L., Long, D., Quiring, S.M. and Shen, Y.J. (2014) Statistical Analysis of the Relationship between Spring Soil Moisture and Summer Precipitation in East China. International Journal of Climatology, 34, 1511-1523. https://doi.org/10.1002/joc.3780 